\title{
Cbfa1-dependent expression of an interferon-inducible p204 protein is required for chondrocyte differentiation
}

\author{
Y Zhang ${ }^{1}$, L Kong ${ }^{1}$, CS Carlson ${ }^{2}$ and C-j Liu ${ }^{*, 1,3}$
}

We reported earlier that an interferon-inducible p204 protein serves as a cofactor of Cbfa1 and promotes osteogenesis. Here we establish that p204 demonstrates prominent expression in growth plate chondrocytes. It is differentially expressed in the course of bone morphogenetic protein-2-triggered chondrocyte differentiation of pluripotent $\mathrm{C} 3 \mathrm{H} 10 \mathrm{~T} 1 / 2$ cells. This expression is probably due to the activation of p204 gene by Cbfa1 and repression by Sox5 transcription factor. Cbfa1 and Sox5 bind to the $5^{\prime}$-flanking regulatory region of p204 gene at their consensus binding elements. Overexpression of p204 accelerates chondrocyte hypertrophy, as revealed by enhanced expression of type X Collagen and matrix metalloproteinase-13; however, knockdown of p204 via an siRNA approach abolishes hypertrophic chondrocyte differentiation. p204 acts as a cofactor of Cbfa1 in chondrocyte hypertrophy: (1) overexpression of p204 augments, whereas suppression of p204 decreases, the Cbfa1-dependent transactivation of a Collagen X-specific reporter gene; (2) p204 enhances Cbfa1-mediated chondrocyte hypertrophy; and (3) p204 associates with Cbfa1 in chondrocyte differentiation. In addition, altered expression of p204 in chondrocyte hypertrophy was accompanied by altered levels of Indian hedgehog $(\mathrm{IHH})$ and parathyroid hormone/parathyroid hormone-related peptide receptor-1 (PTHR1). Collectively, p204 is a novel regulator of chondrocyte differentiation by (1) acting as a coactivator of Cbfa1 and (2) affecting IHH/PTPrP signaling.

Cell Death and Differentiation (2008) 15, 1760-1771; doi:10.1038/cdd.2008.112; published online 18 July 2008

During embryonic development, the majority of bones form through a process of endochondral ossification in which mesenchymal cells first form a cartilaginous template of the future bone. ${ }^{1,2}$ Chondrocytes in the center of these elements undergo hypertrophy and secrete an extracellular matrix that becomes mineralized and allows vascular invasion to occur. ${ }^{3,4}$ Chondrocyte hypertrophy during endochondral ossification is a well-controlled process in which proliferating chondrocytes stop proliferating and differentiate into hypertrophic chondrocytes. This step is crucial for the longitudinal growth and development of long bones, and the only transcription factor shown to be required for hypertrophic chondrocyte differentiation is core binding factor $\alpha-1$ (Cbfa1). ${ }^{1}$ Cbfa1, also known as Runx2, PeBP $2 \alpha \mathrm{A}$, Osf2 or AML3, is a member of the runt family of transcription factors ${ }^{5}$ and expressed not only in all osteoblasts, ${ }^{6}$ but also in hypertrophic chondrocytes ${ }^{7,8}$ and earlier in prechondrogenic mesenchymal condensations. ${ }^{9}$ Transgenic mice generated by overexpressing Cbfa1 in chondrocytes display an acceleration of endochondral ossification. Cbfa1-/mice exhibit a complete lack of ossification and die immediately after birth. ${ }^{10}$ It was found that several Cbfa1-binding proteins, such as retinoblastoma protein $(p R b)^{11}$ and p204, ${ }^{12}$ may also play critical roles in modulating Cbfa1 activity in osteogenesis.

p204 is a member of the interferon-inducible murine p200 family proteins ${ }^{13}$ and consists of 640 amino-acid residues. The C-terminal domain of p204 consists of two homologous partially conserved 200 amino-acid segments (a and b) in which pRb-binding motifs (e.g., LXCXE) are located. Overexpression of p204 is growth inhibitory partially due to its inhibition of ribosomal RNA transcription; p204 binds to the ribosomal DNA-specific upstream binding factor transcription factor and inhibits its sequence-specific binding to DNA. ${ }^{14,15}$ The antiproliferative activity of p204 has been attributed to the binding of p204 to pRb by its pRb-binding LXCXE motifs. ${ }^{14,16}$ However, the antiproliferative activity of p204 does not always depend on pRb. ${ }^{17,18}$ Recently, p204 was found to bind to Ras oncoprotein and might serve as one of the negative feedback inhibitors of Ras activity. ${ }^{18}$

p204 was found to be an important regulator of both skeletal and cardiac muscle differentiation. ${ }^{19-22}$ Overexpression of p204 accelerates muscle formation. ${ }^{21}$ This is due at least in part to the binding of p204 to the inhibitor of differentiation (Id) proteins including Id1, Id2 and Id3, and overcoming the inhibition by the Id proteins of MyoD activity in the case of

${ }^{1}$ Department of Orthopaedic Surgery, New York University Medical Center, New York, NY 10003, USA; ${ }^{2}$ Department of Veterinary Population Medicine, College of Veterinary Medicine, University of Minnesota, St. Paul, MN 55108, USA and ${ }^{3}$ Department of Cell Biology, New York University School of Medicine, New York, NY 10016, USA

*Corresponding author: C-j Liu, Department of Orthopaedic Surgery, New York University Medical Center, 301 East 17th Street, Rm 1608, HJD, New York, NY 10003, USA. Tel: + 212598 6103; Fax: + 212598 6096; E-mail: chuanju.liu@med.nyu.edu

Keywords: chondrocyte differentiation; interferon; Cbfa1; PTHrP signaling; p204

Abbreviations: BMP, bone morphogenetic protein; Cbfa1, core binding factor $\alpha-1$; Co-IP, coimmunoprecipitation; EMSA, electrophoretic mobility shift assay; HRP, horseradish peroxidase; Id, inhibitor of differentiation; IHH, Indian hedgehog; MMP-13, matrix metalloproteinase-13; PCR, polymerase chain reaction; PTHR1, parathyroid hormone/parathyroid hormone-related peptide receptor-1; PTHrP, parathyroid hormone-related peptide; RCS, rat chondrosarcoma cell Received 07.4.08; revised 16.6.08; accepted 23.6.08; Edited by M Piacentini; published online 18.7.08 
skeletal muscle differentiation, and Gata4 and Nkx2.5 activity in the case of cardiac myocyte formation. ${ }^{20,22}$ The p204 gene was also isolated as an M-CSF-responsive gene using a gene-trap approach in the interleukin 3 (IL-3)-dependent myeloid FD-Fms cell line. Moreover, forced expression of p204 strongly repressed the IL-3- and M-CSF-dependent proliferation, whereas it promoted the M-CSF-induced macrophage differentiation of FD-Fms cells. ${ }^{23}$

We previously reported that p204 acted as a transcriptional coactivator of Cbfa1 and therefore enhanced osteoblast differentiation ${ }^{12}$ and that $\mathrm{pRb}$ is an essential linker between p204 and Cbfa1 thereby increasing its activity; ${ }^{24}$ p204, pRb, Cbfa1 and Ids form a protein interaction network and act in concert in regulating the differentiation of pluripotent $\mathrm{C} 2 \mathrm{C} 12$ to osteoblasts. ${ }^{25}$ In this study, we describe the expression and function of p204 in hypertrophic chondrocyte differentiation as well as the molecular mechanism involved.

\section{Results}

Expression of p204 in growth plate chondrocytes. We previously reported that p204 associates with Cbfa1 and plays an important role in osteoblast differentiation. ${ }^{12,24,25}$ Given that Cbfa1 is also required for the hypertrophic chondrocyte differentiation, we sought to determine whether p204 was also involved in the chondrocyte differentiation. We first examined the expression of p204 in growth plate chondrocytes using immunohistochemistry on tibial growth plates of mouse embryos on postcoital day 18.5. As shown in Figure 1, p204 is highly expressed in differentiating hypertrophic chondrocytes but much lower in both resting and proliferating chondrocytes.
Differential expression of p204 in the course of chondrogenesis. To examine the expression profile of p204 during chondrocyte differentiation in vitro, we used a micromass culture of pluripotent $\mathrm{C} 3 \mathrm{H} 10 \mathrm{~T} 1 / 2$ cell line, a well-established in vitro cell model, for studying chondrogenesis. ${ }^{26}$ As revealed in Figure 2a, p204 protein was not detected until day 5 and day 7 in the bone morphogenetic protein (BMP)-2-induced chondrocyte differentiation of C3H10T1/2 cells, and Collagen $X$, a specific marker for hypertrophic chondrocytes, was also immunopositive at day 7 (Figure 2b), indicating that p204 expression is prehypertrophic and hypertrophic chondrocyte-specific, which is in consistent with its in vivo expression in the growth plate (Figure 1). In addition, p204 mRNA was also strongly induced in chondrogenesis, as assayed by real-time PCR with the same cell model (Figure 2d).

Cbfa1 and Sox5 bind to the promoter of p204 gene both in vitro and in vivo. Next we sought to elucidate the molecular mechanism controlling hypertrophic chondrocyte expression of $\mathrm{p} 204$. The sequence analysis revealed that there exist two Cbfa1- and two Sox5-binding sites in the promoter of p204 gene. These findings, together with the facts that Cbfa1 is an essential transcriptional factor for the hypertrophic chondrocyte formation and Sox5, a critical transcription factor that regulates the transition from proliferating to hypertrophic chondrocytes, promoted us to examine whether Cbfa1 and/or Sox5 associates with the promoter of p204 gene. For this purpose, we first examined whether Cbfa1 and Sox5 were able to bind to p204 promoter in an electrophoretic mobility shift assay (EMSA) (Figure 3a). Three digoxigenin-labeled probes corresponding to first Cbfa1-binding site (Figure $3 \mathrm{a}$, left panel), second Cbfa1binding site (Figure 3a, middle panel) and Sox5-binding sites (Figure $3 a$, right panel) incubated with the nuclear extracts

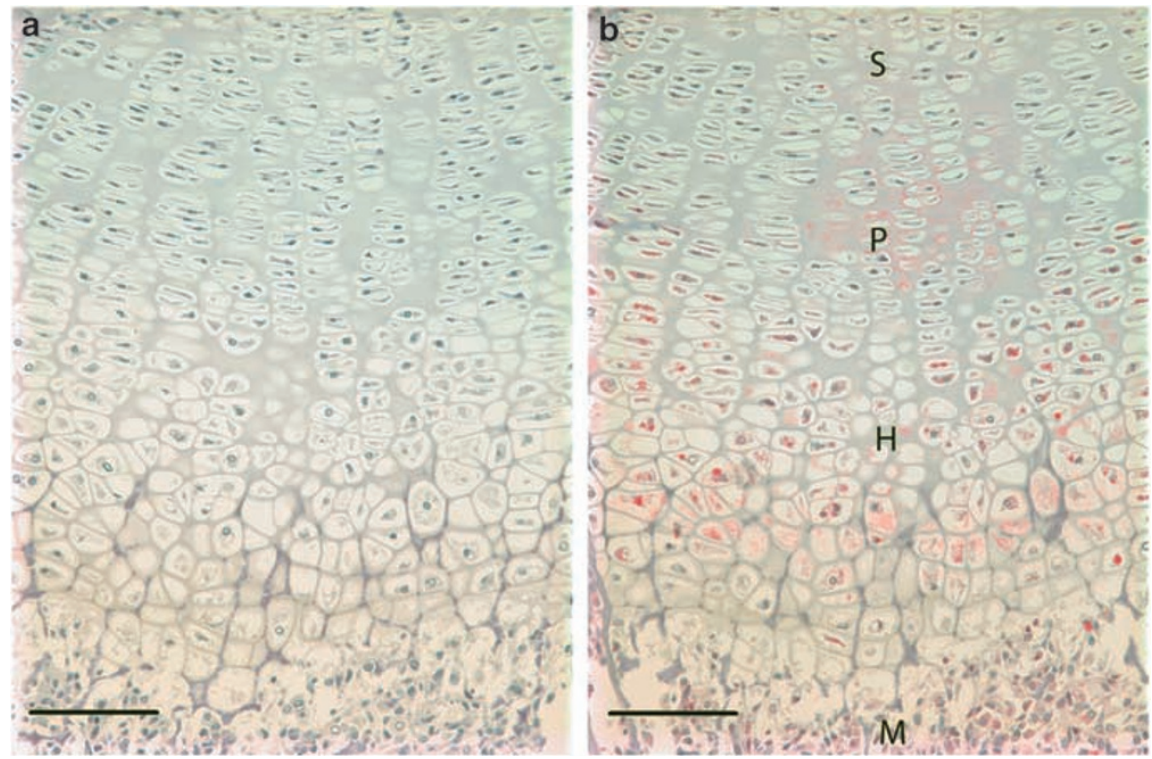

Figure 1 Immunohistochemistry of p204 in tibial growth plates of postcoital day 18.5 mouse embryos: (a) microphotograph of control section using preimmune serum. (b) Microphotograph of section stained with anti-p204 antiserum (red) and counterstained with Mayer's hematoxylin (blue); immunostaining reveals positive nuclear staining in upper hypertrophic and hypertrophic chondrocytes of growth plate. S, resting chondrocytes; $p$, proliferating chondrocytes; $h$, hypertrophic chondrocytes; $m$, bone metaphysis. $\mathrm{Bar}=100 \mu \mathrm{m}$ 

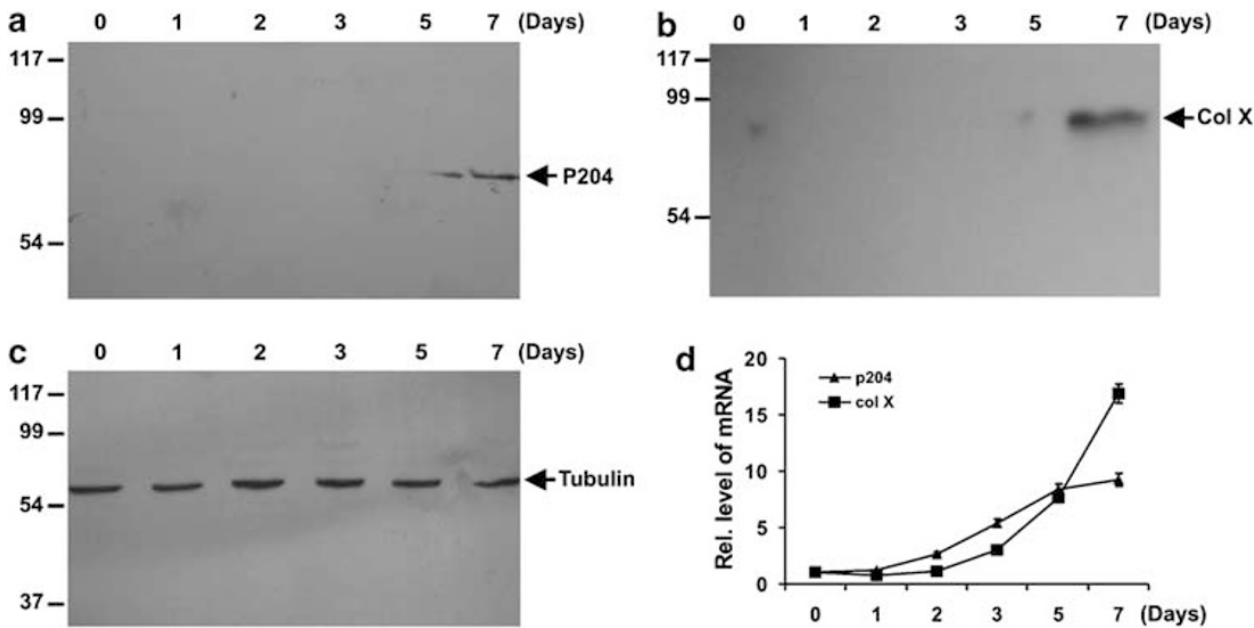

Figure 2 Differential expression of p204 and Collagen X in the course of chondrogenesis in a micromass culture of C3H10T1/2 cells. (a-c) Western blotting assay. After incubation with $300 \mathrm{ng} / \mathrm{ml}$ of BMP-2 for the times indicated, the cells were lysed and $40 \mu \mathrm{g}$ protein samples were assayed for p204 (a), Collagen X (b) and tubulin (c, serving as an internal control) by western blotting with ant-p204, anti-Collagen X or anti-tubulin, respectively; (d) Real-time PCR assay. Total RNA was prepared from micromass cultures of $\mathrm{C} 3 \mathrm{H} 10 \mathrm{~T} 1 / 2$ cells in the presence of $300 \mathrm{ng} / \mathrm{ml}$ recombinant BMP-2 for various time points, as indicated, and the mRNA expression of p204, type X collagen and GAPDH (serving as an internal control) were examined by real-time PCR

prepared from $\mathrm{C} 3 \mathrm{H} 10 \mathrm{~T} 1 / 2$ cells transfected with the mammalian expression plasmid encoding Cbfa1 or Sox5 resulted in a specific Cbfa1/DNA complex (Figure 3a, left and middle panels, lane 2) and Sox5/DNA (Figure 3a, right panel, lane 2). The binding of corresponding probes to Cbfa1 or Sox 5 in vitro was completely competed by excess unlabeled probes (Figure 3a, lane 3), but not unrelated oligodeoxynucleotide (Figure $3 a$, lane 4), indicating that the binding of Cbfa1 and Sox5 to their corresponding binding motifs is sequence-specific.

To determine whether Cbfa1 and Sox5 also bind to p204 promoter in vivo, we next performed chromatin immunoprecipitation (ChIP) assays. ChIP was carried out in C3H10T1/2 cells transfected with an expression plasmid encoding either Cbfa1 or Sox5. After crosslinking with formaldehyde, cell lysates were immunoprecipitated with either control IgG (negative control) or anti-Cbfa1 (or antiSox5) antibodies, and the DNA purified from this immunoprecipitation was analyzed by PCR with PCR primers that spanned the first Cbfa1-binding site (Figure 3b, upper panel), the second Cbfa1-binding site (Figure 3b, middle panel) and Sox5-binding sites (Figure 3b, lower panel) in the p204 promoter. We observed a clear PCR product using DNA isolated from immunoprecipitated complexes with anti-Cbfa1 (Figure 3b, upper and middle panels, lane 2) or anti-Sox5 (Figure 3b, lower panel, lane 2) antibodies but not with control IgG (Figure 3b, upper, middle and lower panels, lane 3), indicating that Cbfa1 and Sox5 bind to their corresponding elements in the p204 promoter in the transfected living cells. To further demonstrate their binding under physiological condition, we also collected the cell lysate of C3H10T1/2 cells during chondrocyte differentiation. Figure $3 \mathrm{c}$ showed that both Cbfa1 and Sox 5 can specifically bind to the promoter of p204 in the course of chondrogenesis.

Cbfa1 activates whereas Sox5 inhibits the transactivation of p204 gene. To determine whether Cbfa1 activates transcription of the p204 promoter using reporter gene assays, two reporter gene plasmids, 204-2C2SBE-luc and 204-1CBE-luc, were used in which segments with CBEs (Cbfa1-binding elements) and SBEs (Sox5-binding elements) from the $5^{\prime}$-flanking region of p204 (-1578 to -1324 and -1578 to +38 ) were linked to the upstream end of a region encoding luciferase in the pGL3 vector (Figure 4a, b; the number preceding 'CBE' and 'SBE', i.e. 1 or 2 , indicates the number of CBEs and SBEs in that plasmid). We transfected both C3H10T1/2 stem cells and RCS (rat chondrosarcoma cell) chondrocytes with these two reporter constructs together with a Cbfa1 expression plasmid. As shown in Figure 4c-e, Cbfa1 activated both p204-specific reporter constructs in both cell lines, and the transactivations were dose-dependent. Intriguingly, higher response to Cbfa1 expression of longer reporter gene (204-2CBE-luc) in RCS chondrocytes than that in $\mathrm{C} 3 \mathrm{H} 10 \mathrm{~T} 1 / 2$ cells was observed, suggesting that chondrocyte-specific cofactor(s) of Cbfa1 might be involved in the Cbfa1-dependent activation of p204 gene. In the case of Sox5 transcription factor, it acted as a repressor of p204 gene, as it inhibited p204-specific reporter gene, and this inhibition was also dose-dependent (Figure 4f).

As Cbfa1 is know to activate the expression of various genes, including other transcription factor(s) in chondrocytes and osteoblasts, the activation of p204 gene by Cbfa1 observed above (Figure 4c-e) might be due to the Cbfa1activable transcription factor(s). To determine whether the increase in the expression of 204-1CBE-luc reporter genes in C3H10T1/2 cells and RCS cells was directly dependent on the Cbfa1-specific sequences, the Cbfa1-specific binding element in pGL3-204-1CBE-luc was altered by either replacing or deleting nucleotides from the sequence (Figure $4 \mathrm{~g}$ ). The replacement of the five CCCAG with AAACT or the deletion of the five CAAGC nucleotides from the $3^{\prime}$-terminal resulted in a strong decrease in the responsiveness to Cbfa1 of the expression of the reporter (Figure 4h). These data suggested 


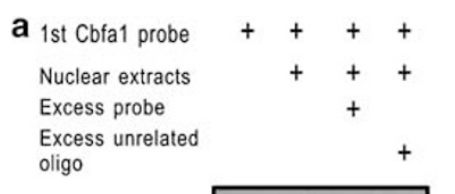

$$
\begin{aligned}
& \text { 2nd Cbfa1 probe } \\
& \text { Nuclear extracts } \\
& \text { Excess probe } \\
& \text { Excess unrelated } \\
& \text { oligo }
\end{aligned}
$$
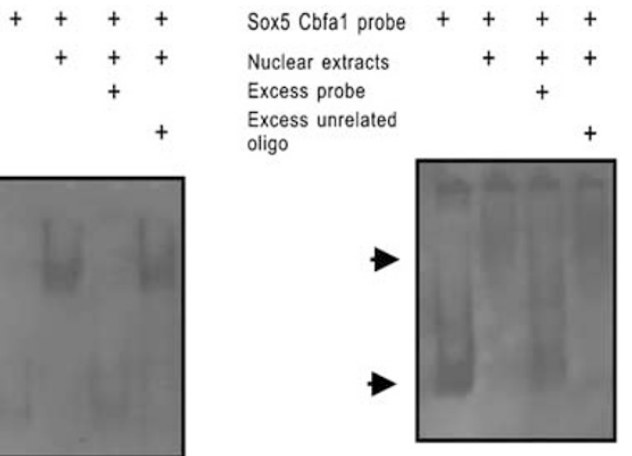

b
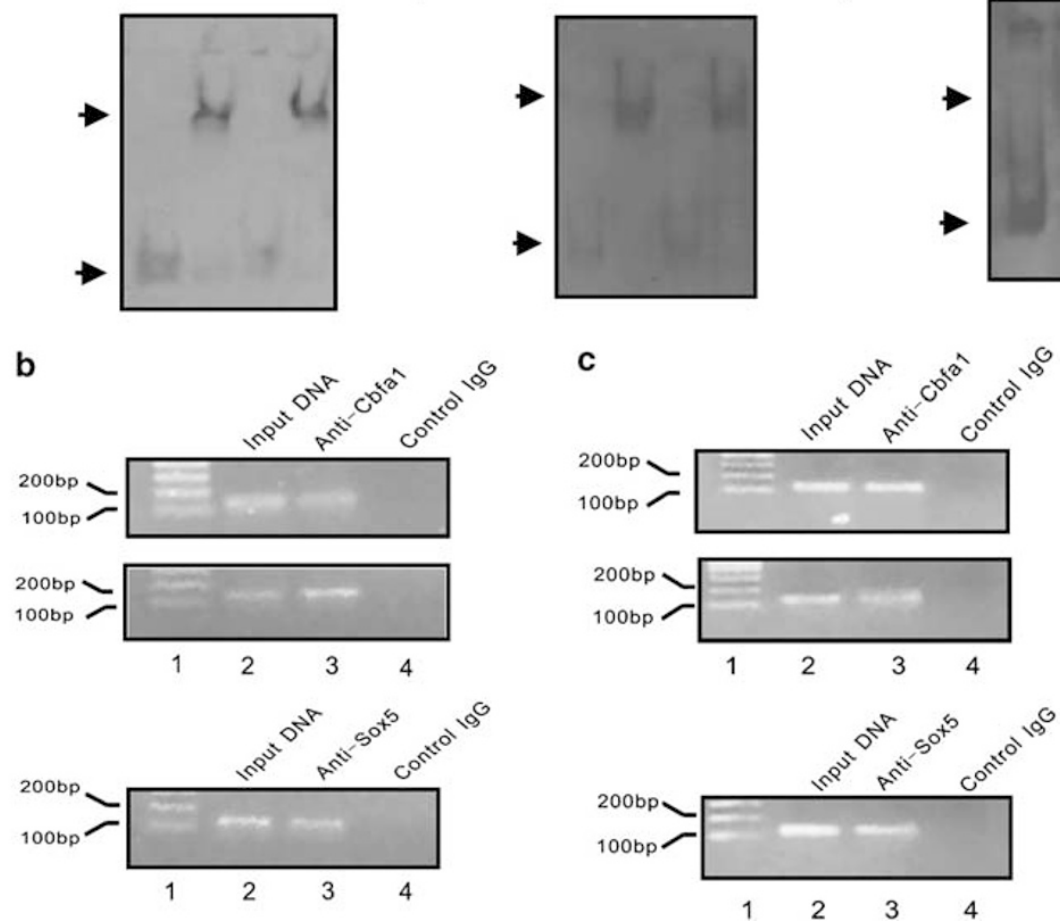

Figure 3 Cbfa1 and Sox 5 bind to the promoter of p204 gene. (a) Cbfa1 and Sox 5 bind to the p204 promoter in vitro (EMSA). Left panel: C3H10T1/2 cells were transfected with Cbfa1 and Sox 5 expression plasmids, and nuclear extracts were incubated with Dig-labeled first Cbfa-binding site in the absence or in the presence of excess of unlabeled probe $(100 \times)$ or Oct2A consensus oligonucleotide (excess unrelated oligo, $100 \times$ ); middle panel: same procedure was followed in addition that Dig-labeled second Cbfa1binding site was employed as probe; right panel: same procedure was followed in addition that Dig-labeled Sox5-binding site was employed as probe. Arrows indicate free probe (bottom) and DNA/protein complex (up). (b) Cbfa1 and Sox5 bind to the p204 promoter in vivo (ChIP). Upper panel: C3H10T1/2 cells transfected with an expression plasmid encoding either Cbfa1 or Sox5 were crosslinked by formaldehyde treatment and lysed. Cell lysates were subjected to immunoprecipitation with control IgG (lane 3) or anti-Cbfa1 antibodies (lane 2). Input DNA (lane 1, serves as positive control) and DNA recovered from the immunoprecipitation were amplified by PCR with the primers spanning the first Cbfa-binding site in the p204 promoter; middle panel: same procedure was followed in addition that primers that span the second Cbfa-binding site were employed; bottom panel: same procedure was followed in addition that primers spanning Sox5-binding site were employed. (c) Cbfa1 and Sox5 bind to the p204 promoter in the course of chondrogenesis. Micromass cultures of C3H10T1/2 cells were treated with $300 \mathrm{ng} / \mathrm{ml}$ of BMP-2 for 5 days and cultures were processed and analyzed as in (b)

that the Cbfa1-dependent increase in the expression of the reporter genes depends on direct association of Cbfa1 and p204 promoter.

Cbfa1 induces whereas Sox5 inhibits the expression of endogenous p204 gene. To further investigate whether this is also true for the endogenous p204 gene expression, we next did real-time PCR assay and western blotting with C3H10T1/2 cells. As revealed in Figure $5 \mathrm{a}, 48 \mathrm{~h}$ after transfection, Cbfa1 remarkably increased the p204 gene expression (approximately six- to sevenfold increase), whereas transfection of Sox5 led to an approximately $50 \%$ inhibition in the level of p204 mRNA (Figure 5b). These results were also verified by western blotting at protein level (Figure 5c, d). These data clearly indicated that Cbfa1 and Sox5 are able to regulate endogenous p204 gene expression.

Overexpressing p204 enhances hypertrophic chondrocyte differentiation. To gain understanding of the role of p204 in chondrocyte hypertrophy, we examined the effect of overexpression of p204 on chondrogenesis in micromass cultures of $\mathrm{C} 3 \mathrm{H} 10 \mathrm{~T} 1 / 2$ and prechondrogenic ATDC5 cells. C3H10T1/2 or ATDC5 cells were infected with adenovirus encoding p204 (Ad-p204) or control GFP (Ad-GFP), and overexpression of p204 was revealed in Figure 6a. Both cultures infected with Ad-p204 or control adenovirus were cultured in the presence of BMP-2 or insulin, and RNA was extracted every other day for real-time RT-PCR. Hypertrophic chondrocyte differentiation was revealed by examining the expression of Collagen $X$ and matrix metalloproteinase-13 (MMP-13), two marker genes widely used for chondrocyte maturation and hypertrophy. As shown in Figure 6b-e, markedly enhanced expressions of Collagen $X$ and MMP-13 in Ad-p204-infected cells were observed compared with those in control cell lines, suggesting that p204 is a positive mediator for chondrocyte hypertrophy.

Knockdown of p204 inhibits hypertrophic chondrocyte differentiation. Having known that p204 can enhance hypertrophic chondrocyte differentiation, we next determined whether endogenous p204 is required for chondrocyte 
a

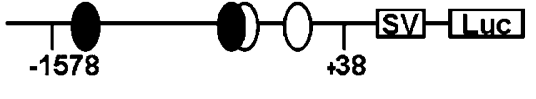

pGL3-204-2C2SBE-IUC

C

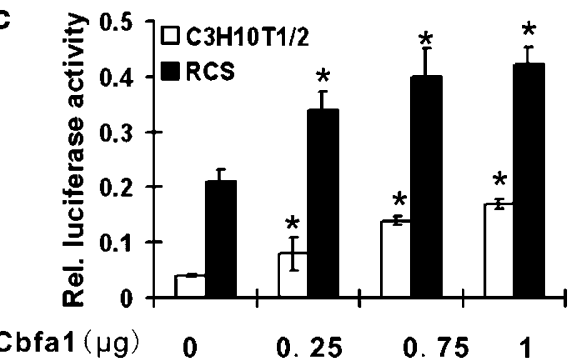

e

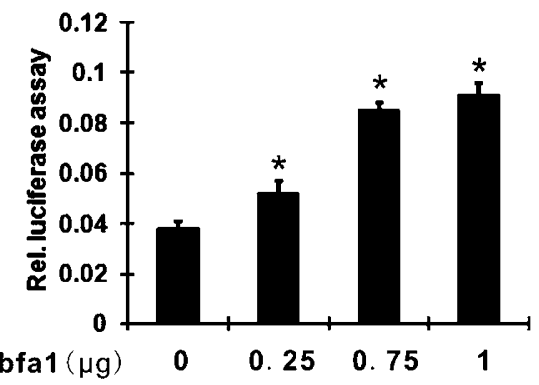

g
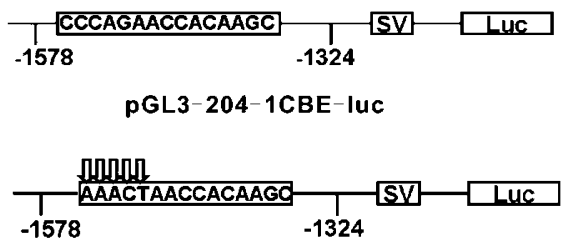

PGL3-204-1CBE (mut1) -luc

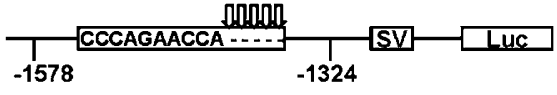

pGL3-204-1CBE (mut2)-luc b

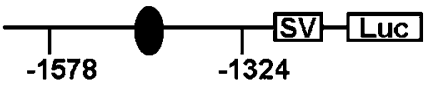

pGL3-204-1CBE-IUC

d
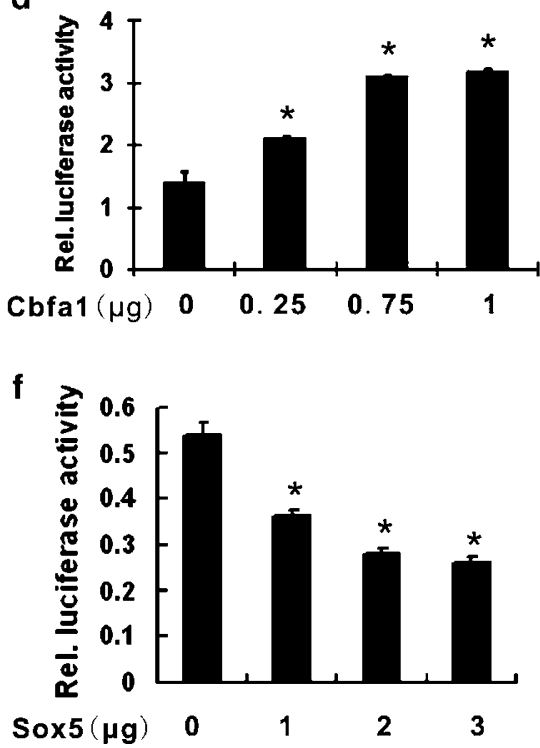

h

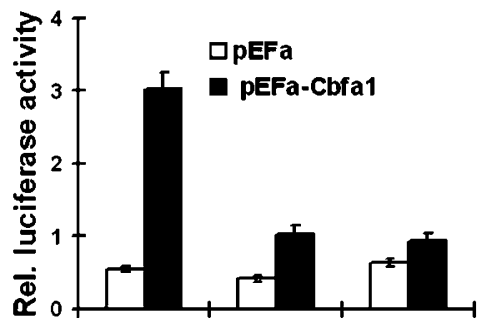

Figure 4 Cbfa1 activates whereas Sox5 represses the transactivation of p204-specific reporter genes. (a and $\mathbf{b}$ ) Schematic structures of two p204-specific reporter genes. The indicated segments from the 5'-flanking region of the p204 gene were linked to an SV40 promoter ('SV') and a DNA segment encoding luciferase ('Luc'). Black and open ovals indicate CBEs (Cbfa1-binding elements) and SBEs (Sox5-binding elements); numbers indicate distances in nucleotides from the first nucleotide of intron 1. (c) Cbfa1 activates the longer p204-specific reporter construct 204-2C2SBE-luc in both C3H10T1/2 pluripotent cells and RCS chondrocytes. The reporter gene and the pCMV-gal internal control plasmid were transfected into cells together with the $\mathrm{pEF} \alpha$-Cbfa1 expression plasmid. At $48 \mathrm{~h}$ after transfection, the cultures were harvested and the luciferase and $\beta$-galactosidase activities were determined; The data shown are the mean levels of luciferase activity from three independent experiments, analyzed in triplicate and normalized by $\beta$-gal activity. ${ }^{*} P<0.05$. (d) Cbfa1 activates the shorter p204-specific reporter construct 204-1CBE-luc in C3H10T1/2 cells. The same procedure as described in (c) was followed; (e) Cbfa1 activates shorter p204-specific reporter construct 204-2CBE-luc in RCS cells. The same procedure as described in (c) was followed; (f) Sox5 inhibits the activity of p204-specific reporter construct 204-2C2SBE-luc in C3H10T1/2 cells. The same procedure as described in (c) was followed; (g) diagrams show the alterations in the first of the Cbfa1-binding sites in the 204-1CBE-luc reporter gene. Mutant nucleotides are indicated by arrows and deleted nucleotides by arrows with minus signs. (h) Cbfa1-dependent transactivation of p204 gene was dramatically reduced when Cbfa1-binding site was mutated. The wild-type or mutant reporter gene specified and the pCMV-gal internal control plasmid were transfected into RCS cells together with $\mathrm{pEF} \alpha$ vector (control) or pEF $\alpha$-Cbfa1 expression plasmid, and the same procedure as described in (c) was followed

hypertrophy by knocking down p204 using small interfering RNA (siRNA) approach in C3H10T1/2 cells and ATDC5 cells. A real-time PCR was performed to verify the RNA level of p204 in both cells. As shown in Figure 7a and d, transfection with pSuper-p204 resulted in approximately 85 and $80 \%$ reduction in p204 mRNA in C3H10T1/2 cells and ATDC5 cells, respectively. Micromass cultures of $\mathrm{C} 3 \mathrm{H} 10 \mathrm{~T} 1 / 2$ cells or ATDC5 cells transfected with pSuper-p204 (si p204) or control vector (CTR) were treated with BMP-2 or insulin for various time points. As shown in Figure $7 \mathrm{~b}$ and $\mathrm{e}$, knockdown of p204 completely abolished the Collagen $X$ induction during chondrocyte differentiation. In addition, induced expression of MMP-13 in the course of chondrocyte differentiation was also largely blocked by knockdown of p204 (Figure 7c and f). These findings clearly indicated that endogenous p204 is required for chondrocyte hypertrophy. 

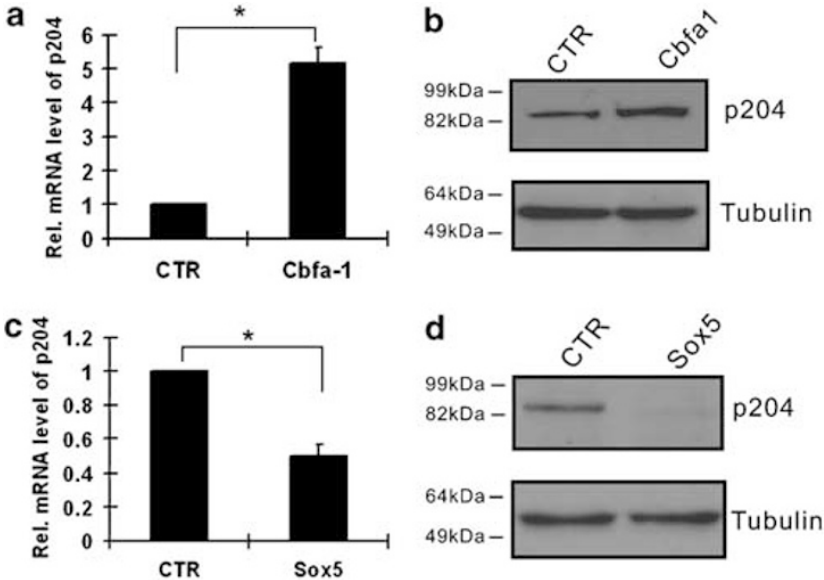

Figure 5 Cbfa1 induces whereas Sox 5 inhibits the expression of endogenous p204 gene. (a) Cbfa1 increases the level of p204 mRNA. C3H10T1/2 cells transfected with a Cbfa1 expression plasmid or control vector were cultured for $48 \mathrm{~h}$ and endogenous p204 gene expression was determined by real-time PCR. Expression of p204 was normalized against the 18S rRNA endogenous control. The normalized values were then calibrated against the control value. The units are arbitrary, and the left bar indicates a relative level of p204 mRNA of $1 ;{ }^{*} P<0.05$. (b) Cbfa1 increases the level of p204 protein. The same cultures were used to detect the protein level of p204 by western blotting. Tubulin protein serves as an internal control; (c) Sox5 reduces the level of p204 mRNA. C3H10T1/2 cells transfected with an Sox 5 expression plasmid or control vector were processed and analyzed as described in (a). (d) Sox5 reduces the level of p204 protein. C3H10T1/2 cells transfected with an Sox5 expression plasmid or control vector were processed and analyzed as described in (b)

p204 associated with Cbfa1 in the course of chondrocyte differentiation. We next sought to elucidate the molecular mechanism by which p204 mediates chondrocyte hypertrophy by determining whether p204 also associates with Cbfa1 in C3H10T1/2 cells and in chondrocyte hypertrophy, as it does in osteoblast differentiation. ${ }^{12}$ To test whether p204 binds to Cbfa1 in C3H10T1/2 cells, we cotransfected Cbfa1 and p204 expression plasmids into C3H10T1/2 cells and performed a coimmunoprecipitation (Co-IP) assay. Briefly, extracts from $\mathrm{C} 3 \mathrm{H} 10 \mathrm{~T} 1 / 2$ cells $48 \mathrm{~h}$ after transfection were first incubated with control IgG (negative control) or anti-Cbfa1 antibodies, and the immunoprecipitated complexes were detected by western blotting with anti-p204 antiserum. A p204-specific band was present in the immunoprecipitated complexes brought down by antiCbfa1 (Figure 8a, lane 3), but not by control antibodies, demonstrating that p204 specifically associates with Cbfa1 in the transfected C3H10T1/2 cells.

To examine whether p204 binds to Cbfa1 in chondrocyte differentiation, micromass culture of C3H10T1/2 cells treated with BMP-2 for 7 days were harvested and a Co-IP assay was performed. As shown in Figure $8 b$, anti-Cbfa1 antibody efficiently brought down p204 protein, whereas control antibody could not, indicating that p204 and Cbfa1 form a protein complex in hypertrophic chondrocyte differentiation. It is worth noting that the expression of Cbfa1 in C3H10T1/2 cells transfected with Cbfa1 and p204 expression plasmids and treated with BMP-2 was also revealed using immunoblotting with anti-Cbfa1 antibody (Figure 8c). p204 enhances Cbfa1-dependent hypertrophic chondrocyte differentiation. Cbfa1 is required for hypertrophic chondrocyte differentiation and activates Collagen $X$ expression. ${ }^{27}$ We first performed an experiment to determine whether p204 regulates the Cbfa1-dependent transactivation of Collagen $X$ using a reporter construct pGL2Collagen $X\left(\sim 5 \mathrm{~kb} 5^{\prime}\right.$-flanking region of Collagen $X$ gene was cloned into the pGI2 basic reporter vector). As shown in Figure 8d, Cbfa1 was able to activate this reporter construct, and p204 further enhanced this Cbfa1-dependent transactivation, suggesting that p204 is a coactivator of Cbfa1 in chondrocyte hypertrophy. Construct expressing p204 siRNA dramatically repressed Cbfa1-dependent activation of this reporter gene (Figure $8 \mathrm{e}$ ). In both experiments, the control vector ( $p E F 1$ ) showed only basal activity.

To determine whether p204 also affects Cbfa1-dependent chondrocyte hypertrophy, ATDC5 cells were infected with adenovirus encoding p204 (Ad-p204), Cbfa1 (Ad-Cbfa1) or combination, and RNA was extracted at day 7 for real-time RT-PCR. As shown in Figure $8 f$ and g, markedly enhanced expressions of Collagen X and MMP-13 in cells infected with Ad-p204 plus Ad-Cbfa1 were observed compared with those in Cbfa1-infected cells, suggesting that p204 is a cofactor of Cbfa1 in regulating chondrocyte hypertrophy.

p204 inhibits IHH/PTHrP signaling. Signaling molecules Indian hedgehog $(\mathrm{IHH})$ and parathyroid hormone-related peptide (PTHrP) establish a negative feedback loop that regulates the pace of chondrocyte hypertrophy. We next examined whether p204 affects this signaling pathway in chondrocyte hypertrophy. The micromass cultures of both p204-overexpressing (p204) and control (CTR) C3H10T1/2 cells (Figure 9a and $c$ ) or ATDC5 (Figure 9b and d) were cultured in the presence of BMP-2 or insulin for various time points, as indicated, and the real-time PCR was performed. Compared with the control, p204 enhanced the expression of $\mathrm{IHH}$ (Figure 9a and b), whereas it dramatically suppressed the expression of PTHrP receptor-1 (PTHR1) (Figure 9c and d) in both cell models tested. Conversely, knockdown of p204 using siRNA approach totally abolished $\mathrm{IHH}$ induction and enhanced PTHR1 expression in chondrocyte differentiation of both C3h10T1/2 and ATDC cells. Taken together, these results indicated that p204 also mediates $\mathrm{IHH} / \mathrm{PTHrP}$ signaling, which is critical for hypertrophic chondrocyte differentiation. ${ }^{3}$

\section{Discussion}

p204 is a multifunctional protein involved in the control of cell proliferation and the differentiation of numerous types of cells and tissues including skeletal muscle myotubes, cardiac myocytes, macrophages and osteoblasts. ${ }^{12,14,15,19-24}$ The current study sought to elucidate the role of p204 in chondrogenesis, with the special focus on chondrocyte hypertrophy, and the molecular events underlying this process. p204 demonstrated prominent expression in the growth plate prehypertrophic and hypertrophic chondrocytes (Figure 1) and was found to be induced in the course of chondrocyte differentiation in vitro (Figure 2). This induction appears to be due to the transactivation of $\mathrm{p} 204$ gene by Cbfa1 transcription 

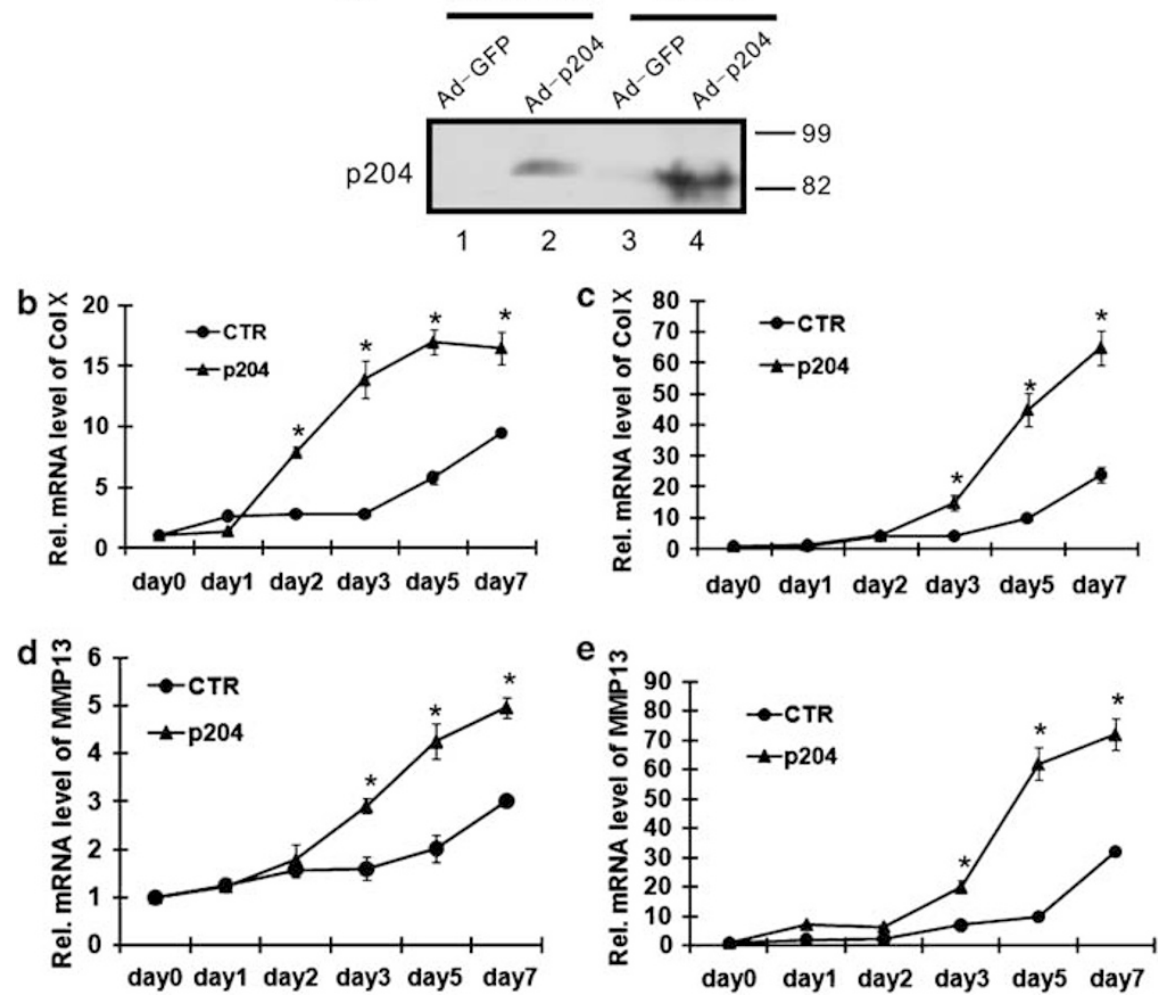

Figure 6 Overexpression of p204 enhances BMP-2-induced chondrocyte hypertrophy, as assayed by Collagen X and MMP-13 expression. (a) C3H10T1/2 and ATDC5 cells were infected with either adenovirus encoding either GFP (Ad-GFP, serves as a control) or p204 (Ad-p204), as indicated, for 2 days, and the level of p204 in the cell lysates was visualized by western blotting with anti-p204 antibody; (b) overexpression of p204 enhances BMP-2-induced Collagen X expression in C3H10T1/2 cells. Transcript levels of Collagen $\mathrm{X}$ were detected by real-time RT-PCR analysis of RNA isolated from micromass cultures of BMP-2-treated C3H10T1/2 cells infected with either Ad-GFP (CTR) or Ad-p204 (p204); ${ }^{*} P<0.05$. (c) Overexpression of p204 enhances BMP-2-induced Collagen X expression in ATDC5 cells. Micromass cultures of BMP-2-treated ATDC5 cells were processed and analyzed as described in (b); (d) overexpression of p204 enhances BMP-2-induced MMP-13 expression in C3H10T1/2 cells. Same cultures as described in (b) were used for examining the expression of MMP-13; (e) overexpression of p204 enhances BMP-2-induced MMP-13 expression in ATDC5 cells. Same cultures as described in (c) were used for examining the expression of MMP-13
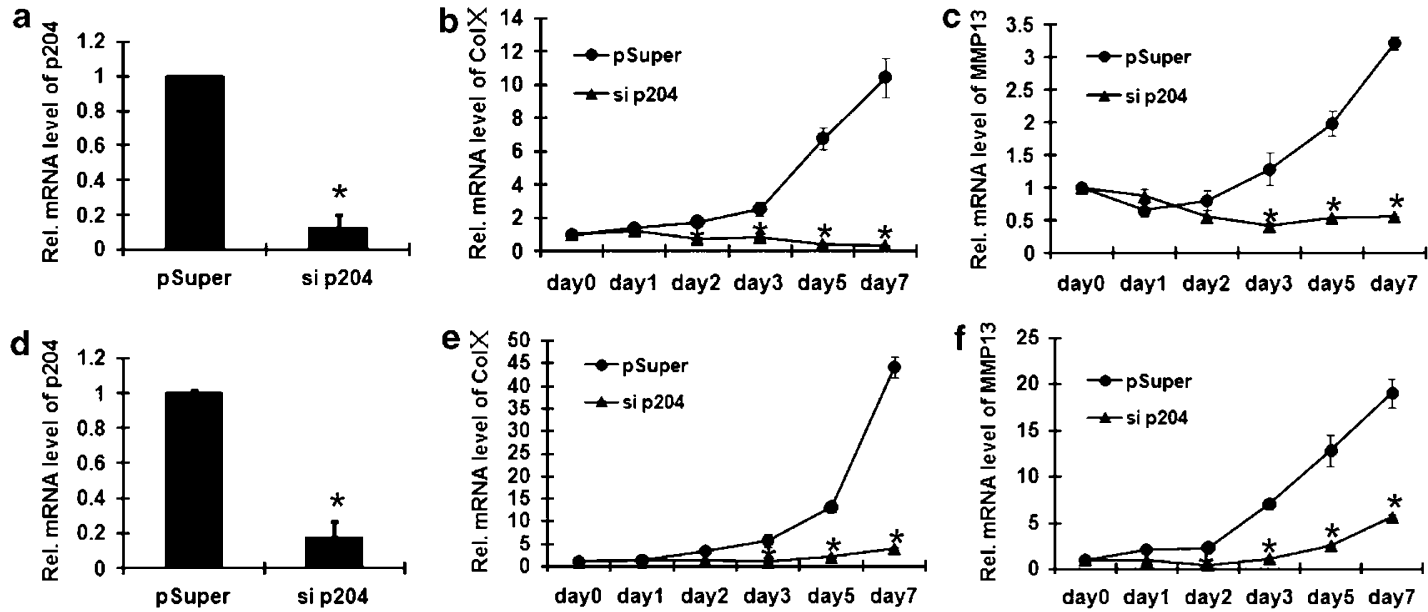

Figure 7 Knockdown of p204 using siRNA approach largely abolishes chondrocyte hypertrophy, as revealed by Collagen X and MMP-13 expression. (a and d) siRNA against p204 mRNA efficiently inhibited expression of endogenous p204 in both C3H10T1/2 (a) and ATDC5 cells (d). Cells were transfected with either an siRNA-p204 expression plasmid pSuper-p204 (si p204) or control vector pSuper (CTR) and total RNA was collected for real-time RT-PCR. Expression of p204 was normalized against the GAPDH endogenous control. The normalized values were then calibrated against the control value, here set as $1 .{ }^{*} P<0.05$. (b and $\mathbf{e}$ ) Repression of p204 totally abolishes BMP-2-induced Collagen X expression in C3H10T1/2 (b) and ATDC5 (e) cells. Transcript level of Collagen X were detected by real-time RT-PCR analysis of RNA isolated from micromass cultures of C3H10T1/2 (b) or ATDC5 (e) cells transfected with pSuper-p204 (si p204) or pSuper vector (CTR) in the presence of $300 \mathrm{ng} / \mathrm{ml}$ of BMP-2 at various time points, as indicated; ${ }^{*} P<0.05$. (c and f) Repression of p204 largely abolishes BMP-2-induced MMP-13 expression in C3H10T1/2 (c) and ATDC5 (f) cells. Transcript levels of MMP-13 were detected by real-time RT-PCR analysis of RNA isolated from micromass cultures of C3H10T1/2 (c) or ATDC5 (f) cells transfected with pSuper-p204 (si p204) or pSuper vector (CTR) in the presence of $300 \mathrm{ng} / \mathrm{ml}$ of BMP-2 at various time points, as indicated. ${ }^{*} P<0.05$ 
factor, whereas Sox5 inhibits the expression of p204 gene (Figures 3-5). p204 functions as a positive regulator of hypertrophic chondrocyte differentiation, because overexpression of p204 enhanced, whereas knockdown of p204 abolished, the expressions of Collagen X and MMP-13, two marker genes for hypertrophic chondrocytes, in the course of chondrocyte differentiation (Figures 6 and 7). The molecular mechanism by which p204 acts as a novel mediator of chondrocyte hypertrophy is, at least in part, due to (1) the binding of p204 to Cbfa1 and acting as its coactivator for
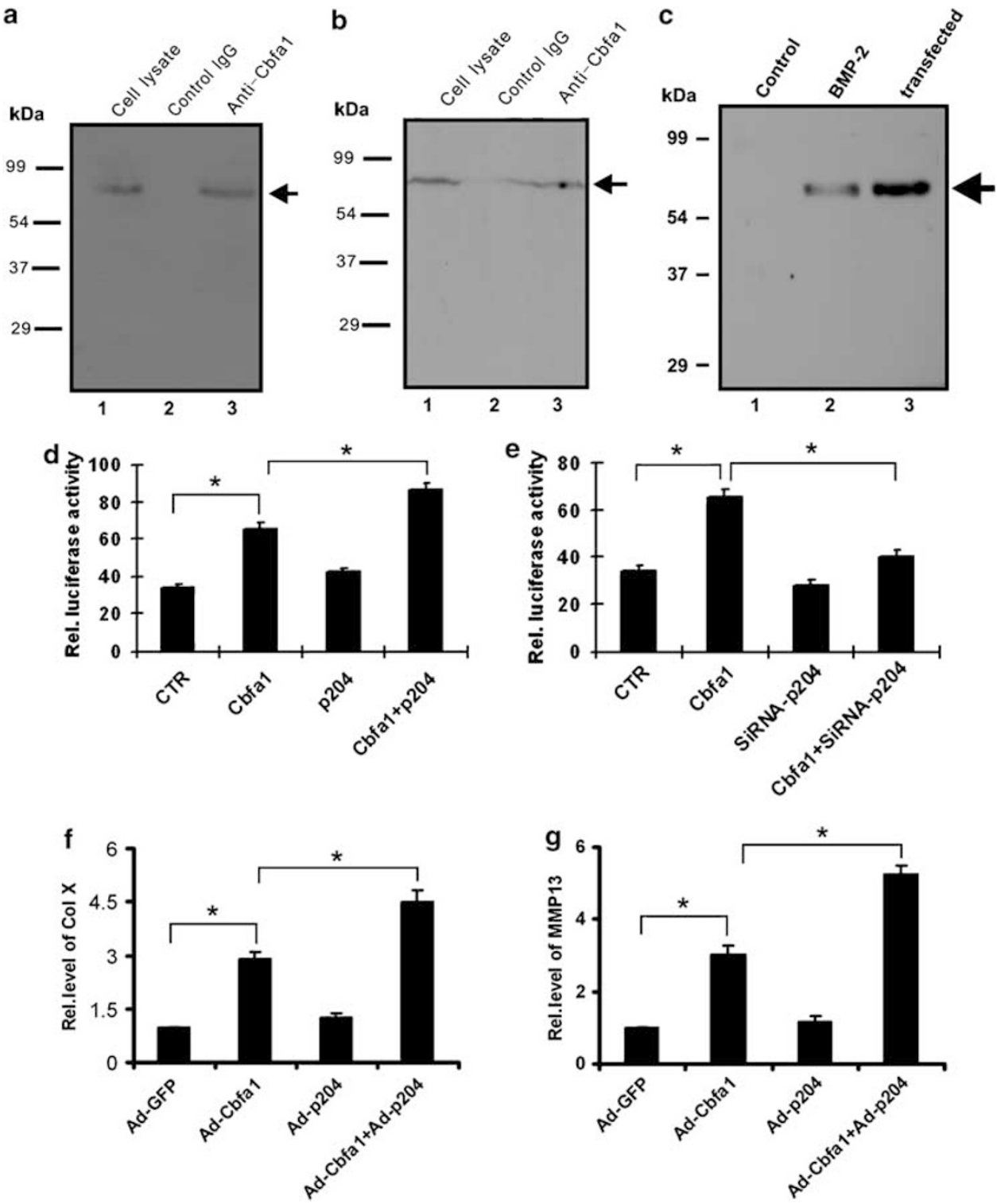

Figure 8 p204 associates with Cbfa1 in chondrogenesis and p204 enhances Cbfa1-mediated chondrocyte hypertrophy. (a) p204 binds to Cbfa1 in vivo. C3H10T1/2 cells were cotransfected with $\mathrm{Cbfa} 1$ and p204 expression plasmids ( $\mathrm{pEF}_{\alpha}-\mathrm{Cbfa1}$ and $\mathrm{pCMV}$-p204). Forty-eight hours later, cell lysates were incubated with either control lgG (lane 2) or Cbfa1 antibodies (lane 3), followed by protein A-agarose. The immunoprecipitated protein complex and cell extracts (lane 1, serves as positive control) were examined by western blotting with anti-p204 antiserum. (b) p204 binds to Cbfa1 in hypertrophic chondrocyte differentiation of C3H10T1/2 cells. Cell lysates prepared from micromass culture of $\mathrm{C} 3 \mathrm{H} 10 \mathrm{~T} 1 / 2$ cells treated with BMP-2 for 7 days were collected and analyzed as described in (a). (c) Western blotting assay of Cbfa1 in the cell lysates used in (a) and (b). Cell lysates prepared from C3H10T1/2 cells (control), C3H10T1/2 cells cotransfected with Cbfa1 and p204 expression plasmids (transfected) or treated with BMP-2 (BMP-2) were examined by western blotting with anti-Cbfa1 antibody. (d) p204 enhances Cbfa1-dependent transactivation of Collagen X. The Col X reporter gene was transfected into $\mathrm{C} 3 \mathrm{H} 10 \mathrm{~T} 1 / 2$ cells together with the control vector, Cbfa1 expression plasmid alone, p204 expression plasmid alone or Cbfa1 plus p204 expression plasmids, as well as a PCMV-gal internal control plasmid. Forty-eight hours after transfection, the cultures were harvested and lysed, and $\beta$-galactosidase and luciferase activity was determined. Luciferase activity was normalized to $\beta$-galactosidase activity. ${ }^{*} P<0.05$. (e) Low level of p204 inhibits Cbfa1-dependent Collagen X transcription. The cultures were processed as described in (d), except that the plasmid expressing p204 was replaced by p204 siRNA expression plasmid pSuper-p204. (f) p204 enhances Cbfa1-induced Collagen X expression in ATDC5 cells. Transcript levels of Collagen X were detected by real-time RT-PCR analysis of RNA isolated from ATDC5 cells infected with either Ad-GFP, Ad-Cbfa1, Ad-p204 or Ad-Cbfa1 plus Ad-p204, as indicated; ${ }^{*} P<0.05$. (g) p204 enhances Cbfa1-induced MMP-13 expression in ATDC5 cells. RNA was extracted as described in (f) and MMP-13 mRNA was detected by real-time RT-PCR 

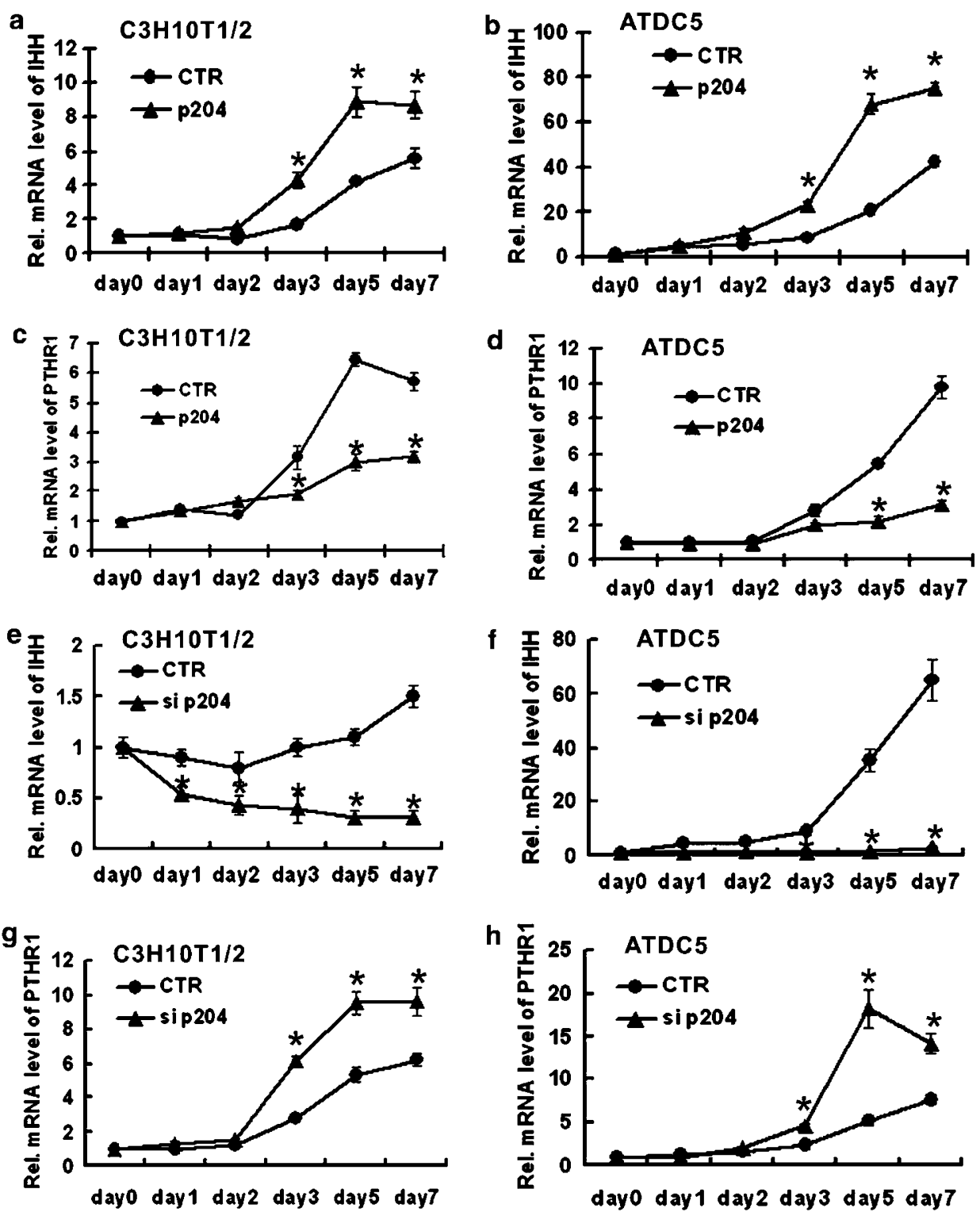

Figure 9 Altered expression of p204 affects the expression of IHH and PTHR1. (a and b) p204 enhances the expression of IHH in chondrocyte differentiation of C3H10T1/2 (a) and ATDC (b) cells. Micromass cultures of C3H10T1/2 (a) and ATDC5 (b) cells infected with either Ad-GFP (CTR) or Ad-p204 (p204) were incubated with $300 \mathrm{ng} / \mathrm{ml}$ of BMP-2 for various time points, as indicated, and the level of $I H H$ was measured by real-time PCR. ${ }^{*} P<0.05$. (c and d) Ectopic expression of p204 leads to remarkable reduction of PTHR1 expression in chondrocyte differentiation of C3H10T1/2 (c) and ATDC5 (d) cells. Same cultures as described in (a) and (b) were used to examine the expression of PTHR1 using real-time PCR. (e and f) Knockdown of p204 via siRNA approach completely abolishes IHH induction in chondrocyte differentiation of C3H10T1/2 (e) and ATDC5 (f) cells. Micromass cultures of C3H10T1/2 (e) and ATDC5 (f) cells transfected with either pSuper (CTR) or pSuper-p204 (si p204) were incubated with $300 \mathrm{ng} / \mathrm{ml}$ of BMP-2 for various time points, as indicated, and the level of $\mathrm{IHH}$ was determined by real-time PCR. ${ }^{*} P<0.05$. ( $(\mathbf{g}$ and $\mathbf{h})$ Knockdown of p204 via siRNA approach enhances PTHR1 expression in chondrocyte differentiation of $\mathrm{C} 3 \mathrm{H} 10 \mathrm{~T} 1 / 2(\mathbf{g})$ and ATDC5 $(\mathbf{h})$ cells. Same cultures as described in (a) and (b) were used to examine the expression of PTHR1 using real-time PCR

hypertrophic chondrocyte formation (Figure 8) and (2) affecting $\mathrm{IHH} / \mathrm{PTHrP}$ signaling (Figure 9), which is known to be important in controlling chondrocyte hypertrophy. ${ }^{3}$

Because of the fact that p204 is highly expressed in the prehypertrophic and hypertrophic chondrocytes in the growth plate (Figures 1 and 2), this study focuses on the role of p204 in regulating hypertrophic chondrocyte differentiation as well as the molecular events involved (Figures 6-9). Although p204 exhibits weak expression in the resting and proliferating chondrocytes under physiological conditions (Figure 1), p204 expression may be altered and affects other stages of chondrogenesis under pathologic conditions; indeed, ectopic expression of p204 also affects the expression of early markers for chondrogenesis, including Sox9 and Collagen II (not shown).

Both Cbfa1 and Sox5, two transcription factors critical for hypertrophic chondrocyte differentiation, directly bind to the $5^{\prime}$-flanking regulatory region of p204 gene at their consensus binding sites and regulate p204-specific reporter constructs and endogenous p204 gene (Figures 3-5). The findings that induction of p204 promoter activity by Cbfa1 in reporter gene assay was less than that in p204 mRNA and protein levels induced by Cbfa1 (Figures 4 and 5) may be due to the fact that 
$5^{\prime}$-flanking regulatory region $(-1578$ to +38$)$ of p204 gene cloned in reporter construct may not contain entire regulatory elements responding to Cbfa1. Because Sox6, a highly homologous molecule of Sox5, was coexpressed with Sox5 in chondrogenesis and these two transcription factors cooperatively activate the type II collagen gene, ${ }^{28}$ we also examined whether Sox 6 regulated p204 gene expression. To our surprise, no binding of Sox6 to the p204 promoter was detected and p204 gene expression was not affected by Sox6 (not shown). Further, we also determined whether p204 expression is regulated by PTHrP signaling using immunohistochemistry with the sections of long bone from 18.5-dayold wild-type and PTHrP (-l-) mouse embryos (provided by Drs. Tatsuya Kobayashi and Henry $M$ Kronenberg). Interestingly, p204 expression was elevated in the growth plate-proliferating chondrocytes in PTHrP $(-/-)$ mice when compared with the wild-type control (not shown), indicating that PTHrP signaling negatively regulates p204 expression. These findings, together with the data showing that altered expression of p204 markedly affects the levels of $\mathrm{IHH}$ and PTHR1 (Figure 9), suggest that there might exist a negative feedback regulation between p204 and PTHrP//HH signaling.

As noted, Cbfa1 is an essential central regulator of osteoblast differentiation and hypertrophic chondrocyte formation. Cbfa1 regulates the activity of their target genes by binding to the respective promoter or enhancer elements in a sequence-specific manner. ${ }^{10}$ It can bind to multiple recognition sites in the Collagen X promoter and activates Collagen $X$ reporter constructs. ${ }^{27}$ Growing evidences demonstrate that a variety of Cbfa1-binding proteins regulates the activity of Cbfa1 and plays important roles in skeletogenesis. ${ }^{11,29-37} \mathrm{As}$ described earlier, $\mathrm{pRb}$, whose mutants have been found in osteosarcoma patients, binds to Cbfa1 and acts as its direct transcriptional coactivator. ${ }^{11}$ p204 also associates with Cbfa1 and promotes osteoblast differentiation. ${ }^{12}$ In addition, p204, $\mathrm{pRb}$ and Cbfa 1 form a ternary complex in which $\mathrm{pRb}$ serves as the linker. ${ }^{24}$ Very recently, we established that inhibitors of DNA binding/differentiation (Ids), including Id1, Id2 and Id3, associate with Cbfa1 and inhibit Cbfa1-dependent alkaline phosphatase activity and osteocalcin production. p204, which interacts with both Cbfa1 and Id2, overcame the Id2-mediated inhibition of Cbfa1-mediated osteogenesis. ${ }^{25}$ It remains to be determined whether Ids and $\mathrm{pRb}$ are expressed in the hypertrophic chondrocytes and participate in the regulation of chondrocyte hypertrophy by Cbfa1 and p204.

On the basis of the data in the literature, ${ }^{3,9,27,38}$ our earlier findings ${ }^{12}$ and the results of this study, we propose a model for the role of p204 - specifically, its expression and function - in chondrocyte differentiation (Figure 10). Cbfa1, an essential transcriptional factor for hypertrophic chondrocyte formation, drives the hypertrophic chondrocyte-specific expression of p204 gene; p204, which associates with Cbfa1, acts as a necessary cofactor of Cbfa1 in stimulating hypertrophic chondrocyte differentiation. Thus, p204 and Cbfa1 form a positive feedback regulation loop, whereas Sox5, another transcription factor important for chondrocyte hypertrophy, suppresses the expression of p204 gene. As chondrocytes go through a program of proliferation and then further differentiation into hypertrophic chondrocytes, PTHrP/PTHrP receptor signaling keeps chondrocytes proliferating and

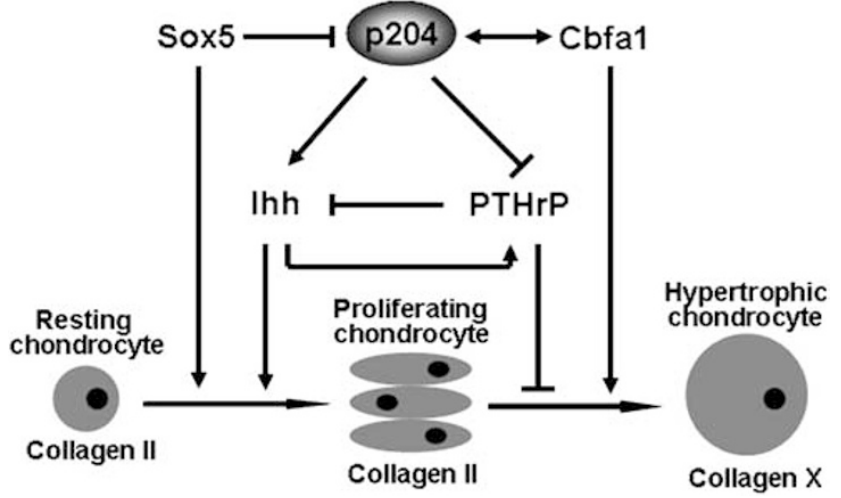

Figure 10 A proposed model for explaining the expression, regulation and function of p204 in chondrocyte differentiation. The data in the literature and in this study are indicated with 'black' and 'color' line respectively. The symbol ' $\rightarrow$ ' and 'indicate 'stimulation' and 'inhibition' respectively

delays their further differentiation. $\mathrm{IHH}$ acts to increase the synthesis of PTHrP and to accelerate the differentiation of proliferative chondrocytes. Thus, IHH and PTHrP establish a negative feedback loop that regulates the pace of hypertrophic chondrocyte differentiation. ${ }^{3,39}$ p204 inhibits PTHrP/IHH signaling by stimulating $\mathrm{IHH}$, whereas repressing PTHR1 expression. Collectively, p204, a target of Cbfa1 and Sox5 transcription factor, regulates hypertrophic chondrocyte differentiation by acting as a coactivator of Cbfa 1 and affecting $\mathrm{PTHrP} / \mathrm{lHH}$ signaling.

\section{Materials and Methods}

Plasmid constructs. To generate wild-type and two mutants of the pGL3204-1CBE-luc reporter plasmid, the corresponding segments were amplified using PCR with the following primers: $5^{\prime}$-AAGCGCTAGCCCTCAGCTGTG- $3^{\prime}$ and $5^{\prime}$-AAG CAGATCTGTGTATGGCAGC-3' for wild-type 204-1CBE-luc; $5^{\prime}$-ccttgttggcagttggt ggttaaataaactaaccacaagctgttgggaactaaaaaggggg- $3^{\prime}$ and $5^{\prime}$-cccccttttagttcccaacag cttgtggttagtttatttaaccaccaactgccaacaagg- $3^{\prime}$ for mut 1 ; and $5^{\prime}$-ccttgttggcagttggtggtta aatcccagaacca(CAAGC)tgttgggaactaaaaaggggg- $3^{\prime}$ and $5^{\prime}$-cccccttttagttcccaaca (GCTTG)tggttctgggatttaaccaccaactgccaacaagg- $3^{\prime}$ for mut 2 (the mutated nucleotides in the primers are underlined, and the deleted nucleotides are enclosed in parentheses and lowercased; see Figure 4). PCR products were inserted into the $\mathrm{pGL} 3$ vector.

To generate p204 siRNA expression constructs, siRNA corresponding to the coding sequence of p204 gene $\left(5^{\prime}\right.$-aatgcaaatgccagcccta-3') was cloned into an siRNA expression pSUPER vector (OligoEngine, Seattle, WA, USA) according to the manufacturer's instructions. Briefly, equimolar amounts of complementary sense and antisense strands were separately mixed, annealed and slowly cooled to $10^{\circ} \mathrm{C}$ in a $50-\mu l$ reaction buffer ( $100 \mathrm{mM} \mathrm{NaCl}$ and $50 \mathrm{mM}$ HEPES, $\mathrm{pH}$ 7.4). The annealed oligonucleotides were inserted into the Bgnl/Hindlll sites of pSUPER vector.

All constructs were verified by nucleic acid sequencing; subsequent analysis was performed using BLAST software (available at http://www.ncbi.nlm.nih.gov/blast)).

Cell culture. The micromass culture was performed as described previously. ${ }^{26}$ Briefly, trypsinized C3H10T1/2 cells were resuspended in DMEM with $10 \% \mathrm{FBS}$ at a concentration of $10^{6}$ cells per $\mathrm{ml}$, and six drops of $100 \mu$ l of cells were placed in a 60 -mm tissue culture dish (Becton Dickinson). After $2 \mathrm{~h}$ incubation at $37^{\circ} \mathrm{C}, 1 \mathrm{ml}$ of DMEM containing $10 \%$ FBS and BMP-2 protein $(300 \mathrm{ng} / \mathrm{ml})$ was added. The media was replaced approximately every 2-3 days. To test the effect of overexpression of p204 protein on chondrogenesis, C3H10T1/2 cells were infected with p204 expression adenovirus ${ }^{24,25}$ or control GFP adenovirus at the multiplicity of infection of 50 before micromass culture. To test the effect of knocking down p204 on chondrogenesis, C3H10T1/2 cells were transfected with p204 siRNA expression plasmid (pSuper-p204) or control plasmid (pSuper) before micromass culture. 
Mouse chondrogenic ATDC5 cells were maintained in a medium consisting of a 1:1 mixture of DME medium and Ham's F-12 medium (Flow Laboratories, Irvine, UK) containing 5\% FBS (GIBCO BRL, Gaithersburg, MD, USA), $10 \mu \mathrm{g} / \mathrm{ml}$ human transferrin (Boehringer $\mathrm{GmbH}$, Mannheim, Germany) and $30 \mathrm{nM}$ sodium selenite (Sigma Chemical Co., St. Louis, MO, USA), at $37^{\circ} \mathrm{C}$ in a humidified atmosphere of $5 \% \mathrm{CO}_{2}$ in air. The ATDC5 cells were seeded at a density of $3 \times 10^{5}$ cells per well in six-well cell-culture plates (Corning, Slangerup, Denmark). To induce chondrogenesis, cells were cultured in the maintenance medium supplemented with $10 \mathrm{mg} / \mathrm{ml}$ human insulin (Sigma-Aldrich). The medium was replaced every other day. For adenovirus (Ad-p204, Ad-Cbfa1 or Ad-GFP) infection and pSuper-p204 plasmid transfection, same protocol was followed as done with C3H10T1/2 cells.

Immunohistochemistry. Sections of postcoital day 18.5 wild-type and Pthrp knockout mouse embryos were deparaffinized, rehydrated and placed in Tris buffer (10 mM Tris- $\mathrm{HCl}(\mathrm{pH} 8.0), 150 \mathrm{mM} \mathrm{NaCl})$. Serum block was applied for $30 \mathrm{~min}$ at room temperature before incubation of the primary antibody. Affinity-purified rabbit anti-mouse p204 was diluted 1:50 and sections were incubated at room temperature for $2 \mathrm{~h}$. For detection, biotinylated secondary antibody and horseradish peroxidase (HRP)-streptavidin complex (Santa Cruz Biotechnology, CA, USA) were used. HRP substrate was used for visualization, and sections were then counterstained with Mayer's hematoxylin.

Immunoblotting analysis. To examine the expression of p204 and Collagen $X$ protein in the course of chondrogenesis, total cell extracts prepared from micromass cultures of C3H10T1/2 cells in the presence of $300 \mathrm{ng} / \mathrm{ml}$ recombinant BMP-2 protein were mixed with $5 \times$ sample buffer $(312.5 \mathrm{mM}$ Tris- $\mathrm{HCl}(\mathrm{pH} 6.8), 5 \%$ $\beta$-mercaptoethanol, $10 \%$ SDS, $0.5 \%$ bromophenol blue, $50 \%$ glycerol). Proteins were resolved on a $10 \%$ SDS-polyacrylamide gel and electroblotted onto a nitrocellulose membrane. After blocking in $10 \%$ nonfat dry milk in Tris buffer saline Tween 20 (10 mM Tris- $\mathrm{HCl}$ (pH 8.0), $150 \mathrm{mM} \mathrm{NaCl}, 0.5 \%$ Tween 20), blots were incubated with either rabbit polyclonal anti-p204 antisera (diluted 1:1000) or deer polyclonal anti-Collagen $X(1: 1000)$ for $1 \mathrm{~h}$. After washing, the respective secondary antibody (HRP-conjugated anti-rabbit immunoglobulin or HRPconjugated anti-deer immunoglobulin; both 1:1000 dilution) was added, and bound antibody was visualized using an enhanced chemiluminescence system (Amersham Biosciences)

RT-PCR. Total RNA was isolated from $300 \mathrm{ng} / \mathrm{ml}$ BMP-2-treated micromass cultures of 10T1/2 cells with the RNeasy mini kit (Qiagen, Alameda, CA, USA) and then reverse-transcribed to CDNA as described in the protocol of the ImpromIIReverse Transcriptase system kit (Promega, Madison, WI, USA). The following sequence-specific primers were synthesized: $5^{\prime}$-ATTTACTGACTTATCTGCCT AC- $3^{\prime}$ and $5^{\prime}$-CAATCTGAATCGTGGTGT- $3^{\prime}$ for p204 and $5^{\prime}$-CTGCTGCTAATGTT CTTGAC- $3^{\prime}$ and $5^{\prime}$-ACTGGAATCCCTTTACTCTTT- $3^{\prime}$ for Collagen $X$. The following pair of oligonucleotides was used as internal controls: $5^{\prime}$-ACCACAGTCCATGC CATCAC- $3^{\prime}$ and $5^{\prime}$-TCCACCACCCTGTTGCTGTA- $3^{\prime}$ for GAPDH. PCRs were performed for $35 \mathrm{cycles}\left(94^{\circ} \mathrm{C} 1 \mathrm{~min}, 60^{\circ} \mathrm{C} 1 \mathrm{~min}\right.$ and $\left.72^{\circ} \mathrm{C} 1 \mathrm{~min}\right)$ with a final elongation for $10 \mathrm{~min}$ at $72^{\circ} \mathrm{C}$. GAPDH was also amplified and employed as an internal control for 35 cycles $\left(94^{\circ} \mathrm{C} 1 \mathrm{~min}, 55^{\circ} \mathrm{C} 1 \mathrm{~min}\right.$ and $\left.72^{\circ} \mathrm{C} 1 \mathrm{~min}\right)$. The PCR product was analyzed by $1 \%$ agarose gel electrophoresis.

Electrophoretic mobility shift assays. Nuclear proteins from micromass cultures of $\mathrm{C} 3 \mathrm{H} 10 \mathrm{~T} 1 / 2$ cells transfected with Cbfa- 1 or Sox 5 expression plasmids or treated with BMP-2 were extracted as described previously. ${ }^{40}$ Oligonucleotides corresponding to -1445 to -1420 (the first Cbfa1-binding site), -638 to -600 (the second Cbfa1-binding site) and -552 to -530 (the Sox5-binding site) of the mouse p204 promoter $^{21}$ were synthesized. The probes were labeled with digoxigenin (DIG)-11-ddUTP, and EMSAs were performed using a DIG gel shift kit (Roche Applied Science). Competition experiments were performed by preincubating nuclear extract with excess unlabeled probes or Oct2A consensus oligonucleotide (Roche) before adding labeled oligonucleotides. Reaction mixtures were incubated for $20 \mathrm{~min}$ at room temperature. Samples were subjected to electrophoresis on a native $5 \%$ polyacrylamide gel run in $0.5 \times \mathrm{TBE}(89 \mathrm{mmol} / \mathrm{I} \mathrm{Tris}-\mathrm{HCl}, 89 \mathrm{mmol} / \mathrm{l}$ boric acid and $2 \mathrm{mmol} / / \mathrm{EDTA}$ ) for $2.5 \mathrm{~h}$ at $100 \mathrm{~V}$. Signal was detected using a chemiluminescent detection system (Roche Applied Science).

Chromatin immunoprecipitation. $\mathrm{C} 3 \mathrm{H} 10 \mathrm{~T} 1 / 2$ cells transfected with $\mathrm{pEF}_{\alpha}$-Cbfa1 or pcDNA-Sox5 plasmids, or treated with BMP-2, were fixed by $1 \%$ formaldehyde for $10 \mathrm{~min}$ before cell lysis. Cell lysates were subsequently sonicated, followed by centrifugation. The input ( $1 \%$ of the supernatant) was used in PCR as a positive control. The supernatant was then precleared using protein A agarose/ salmon sperm DNA for 30 min at $4^{\circ} \mathrm{C}$. After centrifugation, the supernatant was then used for immunoprecipitation using anti-Cbfa1 or anti-Sox5 antibody or control lgG and incubated overnight at $4{ }^{\circ} \mathrm{C}$. The protein/DNA complex was subsequently incubated with protein $\mathrm{A}$ agarose/salmon sperm DNA for $1 \mathrm{~h}$ at $4^{\circ} \mathrm{C}$. The immune complex was collected by centrifugation and then washed five times with the following for 5 min each: once with low-salt immune complex wash buffer, once with high-salt immune complex wash buffer, once with LiCL salt immune complex wash buffer and twice with TE buffer. Histone/DNA complex was eluted from the antibody using elution buffer ( $1 \% \mathrm{SDS}, 0.1 \mathrm{M} \mathrm{NaHCO}_{3}$ ) and added $5 \mathrm{M} \mathrm{NaCl}$ to reverse histone-DNA crosslink by heating for $4 \mathrm{~h}$ at $65^{\circ} \mathrm{C}$. The DNA was then extracted with phenol-chloroform and precipitated with ethanol in the presence of glycogen $(20 \mu \mathrm{g})$ as a carrier. The precipitate was used as a template for PCR amplification. The primers specifically amplified two 120-bp segments spanning Cbfa1-binding sites and one 110-bp segment spanning Sox5-binding site of the p204 gene promoter. The sequences of primers are following: sense CCTTGTTGGCAG TTGGTGGT , antisense CCTGACAGACCAGAGAATAG (for first Cbfa1-binding site); sense AGACCTCAAAACCACAA, antisense GAGTTTTTATTGTAGTA (for second Cbfa1-binding site); sense AAAACCACAATTCTCTG, antisense GAGTTTTTAT TGTAGTA (for Sox5-binding site). PCR was performed under the following conditions: $94^{\circ} \mathrm{C} 5 \mathrm{~min}, 35$ cycles at $94^{\circ} \mathrm{C}$ for $30 \mathrm{~s}, 56^{\circ} \mathrm{C}$ for $30 \mathrm{~s}$ and $72^{\circ} \mathrm{C}$ for $45 \mathrm{~s}$.

Reporter gene assays. C3H10T1/2 and RCS cells were plated at a density of $3 \times 10^{5}$ cells per well in six-well tissue culture plates and transfected with p204-specific reporter plasmids (pGL3-204-1CBE-luc, pGL3-204-2C2SBE-luc, pGL3-204-1CBE(mut1)-luc or pGL3-204-1CBE(mut2)-luc), pEF - -Cbfa1 or pcDNA-Sox5 and pCMV-gal (an internal control for transfection efficiency). Fortyeight hours after transfection, cells were harvested, and luciferase and $\beta$-galactosidase activity was measured using the Bioscan Mini-lum. Relative transcriptional activity was expressed as a ratio of luciferase reporter gene activity from the experimental vector to that from the internal control vector. To test whether p204 affects Cbfa1-dependent transactivation of Collagen X-specific reporter gene, 10T1/2 cells were transfected with Col X-specific reporter construct (pGL4600Intl, generously provided by Dr. J Patrick O'Connor), pCMV-gal plasmid and mammalian expression plasmids (pEF1-Cbfa1 expressing Cbfa1, pCMV204 expressing p204 and pSuper-204 expressing p204 siRNA or various of combinations). The cultures were processed and analyzed as described above.

Quantitative real-time PCR. To examine the effects of Cbfa1 and Sox5 on the expression of p204 gene, C3H10T1/2 or RCS cells were plated at a density of $3 \times 10^{5}$ cells per well in six-well tissue culture plates. One microgram of Cbfa1 expression plasmid $\mathrm{pEF} \mathrm{F}_{\alpha}$-cbfa1 or Sox 5 expression plasmid pcDNA-Sox 5 was then transfected into these cells using Lipofectamine2000. After $48 \mathrm{~h}$, total RNAs were isolated using the RNeasy mini kit (Qiagen, Hilden, Germany) and reversetranscribed into cDNA. Real-time PCR was performed with an ABI 7400 System using the TaqMan EZ RT-PCR kit according to the manufacturer's protocol. TaqMan primers and probes were derived from the commercially available TaqMan ${ }^{\mathbb{R}}$ Assays-on-Demand Gene Expression Products. We select GAPDH as the endogenous control for the real-time PCR relative quantification analysis. PCR cycling conditions were as follows: initial incubation step of $2 \mathrm{~min}$ at $50^{\circ} \mathrm{C}$, reverse transcription of $60 \mathrm{~min}$ at $60^{\circ} \mathrm{C}$ and $94^{\circ} \mathrm{C}$ for $2 \mathrm{~min}$, followed by 40 cycles of $15 \mathrm{~s}$ at $95^{\circ} \mathrm{C}$ for denaturation and $2 \mathrm{~min}$ at $62^{\circ} \mathrm{C}$ for annealing and extension.

In the case of Collagen X, IHH and PTHR1, PCR was run using the SYBR GREEN PCR kit and the following primers were used: sense $3^{\prime}$-gccgcttgtcagtgct aacc- $5^{\prime}$, antisense $3^{\prime}$-cgtaatgctgctgcctattg- $5^{\prime}$ (Collagen X); sense $3^{\prime}$-gctcgtgcctct tgcctaca- $5^{\prime}$, antisense $3^{\prime}$-cgtgttctcctcgtccttga $-5^{\prime}(\mathrm{IHH})$; sense $3^{\prime}$-accgtggctgtgctca tcct- $5^{\prime}$, antisense $3^{\prime}$-ccagcgtgaagccagagtag-5' (PTHR1).

Coimmunoprecipitation. Approximately $500 \mu \mathrm{g}$ of cell extract proteins prepared from $\mathrm{C} 3 \mathrm{H} 10 \mathrm{~T} 1 / 2$ cells cotransfected with Cbfa1 and p204 expression plasmids ( $\mathrm{pEF}_{\alpha}$-Cbfa1 and $\mathrm{pCMV}-\mathrm{p} 204$ ) or BMP-2-treated micromass culture of C3H10T1/2 cells were incubated with anti-Cbfa1 $(20 \mu \mathrm{g} / \mathrm{ml})$ or control rabbit lgG $(25 \mu \mathrm{g} / \mathrm{ml})$ antibodies for $1 \mathrm{~h}$, followed by incubation with $30 \mu \mathrm{l}$ of protein A-agarose (PerkinElmer Life Sciences) at $4^{\circ} \mathrm{C}$ overnight. After washing five times with immunoprecipitation buffer, bound proteins were released by boiling in $20 \mu \mathrm{l}$ of $2 \times$ SDS loading buffer for $3 \mathrm{~min}$. Released proteins were examined by western blotting with anti-p204 antiserum, and the signal was detected using the ECL chemiluminescent system. 
Statistical test. One-way Anova analysis was performed in $\mathrm{R}$ software to determine the significant differences ( $F$ value $>3.35 ; \alpha<0.05)$ of the activity among different doses. In addition, Tukey's test was also used in conjunction with an ANOVA to find significant differences $(P<0.05 ; P<0.01)$ of the levels of genes of interest.

Acknowledgements. We thank Dr. J Patrick O'Connor for Collagen $X$ reporter gene, and Drs. Kosei Ito and Yoneda Toshiyuki for constructs expressing PeBP2 $\alpha$ (Cbfa1), Dr. Renny Franceschi for adenovirus encoding Cbfa1, Dr. Yiming Cheng for data statistical analysis and Anne Undersander for preparation of the immunohistochemistry sections. This work was aided by $\mathrm{NIH}$ research grants AR050620 (C-j Liu), AR052022 (C-j Liu), AR053210 (C-j Liu), AG029388 (C-j Liu) and RR14099 (CS Carlson) and a grant from Arthritis National Research Foundation (C-j Liu).

1. Karsenty G, Wagner EF. Reaching a genetic and molecular understanding of skeletal development. Dev Cell 2002; 2: 389-406.

2. Wagner EF, Karsenty G. Genetic control of skeletal development. Curr Opin Genet Dev 2001; 11: 527-532.

3. Kronenberg HM. PTHrP and skeletal development. Ann N Y Acad Sci 2006; 1068: 1-13.

4. Olsen BR, Reginato AM, Wang W. Bone development. Annu Rev Cell Dev Biol 2000; 16 191-220.

5. Ito $\mathrm{Y}$. Molecular basis of tissue-specific gene expression mediated by the runt domain transcription factor PEBP2/CBF. Genes Cells 1999; 4: 685-696.

6. Ducy P, Zhang R, Geoffroy V, Ridall AL, Karsenty G. Osf2/Cbfa1: a transcriptional activato of osteoblast differentiation. Cell 1997; 89: 747-754.

7. Inada M, Yasui T, Nomura S, Miyake S, Deguchi K, Himeno $M$ et al. Maturationa disturbance of chondrocytes in Cbfa1-deficient mice. Dev Dyn 1999; 214: 279-290.

8. Kim IS, Otto F, Zabel B, Mundlos S. Regulation of chondrocyte differentiation by Cbfa1. Mech Dev 1999; 80: 159-170.

9. Otto F, Thornell AP, Crompton T, Denzel A, Gilmour KC, Rosewell IR et al. Cbfa1, a candidate gene for cleidocranial dysplasia syndrome, is essential for osteoblast differentiation and bone development. Cell 1997; 89: 765-771.

10. Komori T, Yagi H, Nomura S, Yamaguchi A, Sasaki K, Deguchi K et al. Targeted disruption of Cbfa1 results in a complete lack of bone formation owing to maturational arrest of osteoblasts. Cell 1997; 89: 755-764.

11. Thomas DM, Carty SA, Piscopo DM, Lee JS, Wang WF, Forrester WC et al. The retinoblastoma protein acts as a transcriptional coactivator required for osteogenic differentiation. Mol Cell 2001; 8: 303-316.

12. Liu CJ, Chang E, Yu J, Carlson CS, Prazak L, Yu XP et al. The interferon-inducible p204 protein acts as a transcriptional coactivator of Cbfa1 and enhances osteoblast differentiation. J Biol Chem 2005; 280: 2788-2796.

13. Choubey D, Snoddy J, Chaturvedi V, Toniato E, Opdenakker G, Thakur A et al. Interferons as gene activators. Indications for repeated gene duplication during the evolution of a cluster of interferon-activatable genes on murine chromosome 1. J Biol Chem 1989; 264 17182-17189.

14. Liu CJ, Wang $\mathrm{H}$, Lengyel $\mathrm{P}$. The interferon-inducible nucleolar $\mathrm{p} 204$ protein binds the ribosomal RNA-specific UBF1 transcription factor and inhibits ribosomal RNA transcription. EMBO J 1999; 18: 2845-2854

15. Moss T, Stefanovsky VY. At the center of eukaryotic life. Cell 2002; 109: 545-548.

16. Gribaudo G, Riera L, De Andrea M, Landolfo $S$. The antiproliferative activity of the murine interferon-inducible Ifi 200 proteins depends on the presence of two 200 amino acid domains. FEBS Lett 1999; 456: 31-36.

17. Asefa B, Dermott JM, Kaldis P, Stefanisko K, Garfinkel DJ, Keller JR. p205, a potentia tumor suppressor, inhibits cell proliferation via multiple pathways of cell cycle regulation FEBS Lett 2006; 580: 1205-1214.

18. Ding B, Lengyel P. p204 protein is a novel modulator of ras activity. J Biol Chem 2008; 283 5831-5848.

19. Ding B, Liu CJ, Huang Y, Hickey RP, Yu J, Kong $W$ et al. p204 is required for the differentiation of P19 murine embryonal carcinoma cells to beating cardiac myocytes: its expression is activated by the cardiac GATA4, NKX2.5, and TBX5 proteins. $J$ Biol Chem 2006; 281: 14882-14892.
20. Ding B, Liu CJ, Huang Y, Yu J, Kong W, Lengyel P. p204 protein overcomes the inhibition of the differentiation of P19 murine embryonal carcinoma cells to beating cardiac myocytes by Id proteins. J Biol Chem 2006; 281: 14893-14906.

21. Liu C, Wang H, Zhao Z, Yu S, Lu YB, Meyer J et al. MyoD-dependent induction during myoblast differentiation of p204, a protein also inducible by interferon. Mol Cell Biol 2000; 20: 7024-7036

22. Liu CJ, Ding B, Wang H, Lengyel P. The MyoD-inducible p204 protein overcomes the inhibition of myoblast differentiation by Id proteins. Mol Cell Biol 2002; 22: 2893-2905

23. Dauffy J, Mouchiroud G, Bourette RP. The interferon-inducible gene, Ifi204, is transcriptionally activated in response to M-CSF, and its expression favors macrophage differentiation in myeloid progenitor cells. $J$ Leukoc Biol 2006; 79: 173-183.

24. Luan $Y, Y u ~ X P, X u ~ K$, Ding B, Yu J, Huang $Y$ et al. The retinoblastoma protein is an essential mediator of osteogenesis that links the p204 protein to the Cbfa1 transcription factor thereby increasing its activity. J Biol Chem 2007; 282: 16860-16870.

25. Luan Y, Yu XP, Yang N, Frenkel S, Chen L, Liu CJ. p204 protein overcomes the inhibition of Cbfa1-mediated Osteogenic differentiation by Id Helix-Loop-Helix proteins. Mol Biol Cell 2008; 19: 2113-2126.

26. Liu CJ, Prazak L, Fajardo M, Yu S, Tyagi N, Di Cesare PE. Leukemia/lymphoma-related factor a POZ domain-containing transcriptional repressor, interacts with histone deacetylase- 1 and inhibits cartilage oligomeric matrix protein gene expression and chondrogenesis. J Biol Chem 2004; 279: 47081-47091.

27. Zheng Q, Zhou G, Morello R, Chen Y, Garcia-Rojas X, Lee B. Type X collagen gene regulation by Runx2 contributes directly to its hypertrophic chondrocyte-specific expression in vivo. J Cell Biol 2003; 162: 833-842.

28. Lefebvre V, Smits P. Transcriptional control of chondrocyte fate and differentiation. Birth Defects Res C Embryo Today 2005; 75: 200-212.

29. Cui CB, Cooper LF, Yang X, Karsenty G, Aukhil I. Transcriptional coactivation of bonespecific transcription factor Cbfa1 by TAZ. Mol Cell Biol 2003; 23: 1004-1013.

30. Gutierrez S, Javed A, Tennant DK, van Rees M, Montecino M, Stein GS et al. CCAAT/ enhancer-binding proteins (C/EBP) beta and delta activate osteocalcin gene transcription and synergize with Runx2 at the C/EBP element to regulate bone-specific expression. $J$ Biol Chem 2002: 277: 1316-1323.

31. Jin YH, Jeon EJ, Li QL, Lee YH, Choi JK, Kim WJ et al. Transforming growth factor-beta stimulates p300-dependent RUNX3 acetylation, which inhibits ubiquitination-mediated degradation. J Biol Chem 2004; 279: 29409-29417.

32. Schroeder TM, Kahler RA, Li X, Westendorf JJ. Histone deacetylase 3 interacts with Runx2 to repress the osteocalcin promoter and regulate osteoblast differentiation. J Biol Chem 2004; 279: 41998-42007.

33. Sierra J, Villagra A, Paredes R, Cruzat F, Gutierrez S, Javed A et al. Regulation of the bone-specific osteocalcin gene by $\mathrm{p} 300$ requires Runx2/Cbfa1 and the vitamin D3 receptor but not p300 intrinsic histone acetyltransferase activity. Mol Cell Biol 2003; 23: 3339-3351.

34. Yoshida CA, Furuichi T, Fujita T, Fukuyama R, Kanatani N, Kobayashi S et al. Corebinding factor beta interacts with Runx2 and is required for skeletal development. Nat Genet 2002; 32: 633-638.

35. Zhang YW, Yasui N, Ito K, Huang G, Fujii M, Hanai J et al. A RUNX2/PEBP2alpha A/ CBFA1 mutation displaying impaired transactivation and Smad interaction in cleidocranial dysplasia. Proc Natl Acad Sci USA 2000; 97: 10549-10554

36. Zhao M, Qiao M, Harris SE, Oyajobi BO, Mundy GR, Chen D. Smurf1 inhibits osteoblast differentiation and bone formation in vitro and in vivo. J Biol Chem 2004; 279: 12854-12859.

37. Zhao M, Qiao M, Oyajobi BO, Mundy GR, Chen D. E3 ubiquitin ligase Smurf1 mediates core-binding factor alpha1/Runx2 degradation and plays a specific role in osteoblast differentiation. J Biol Chem 2003; 278: 27939-27944.

38. Huang W, Chung UI, Kronenberg HM, de Crombrugghe B. The chondrogenic transcription factor Sox9 is a target of signaling by the parathyroid hormone-related peptide in the growth plate of endochondral bones. Proc Natl Acad Sci USA 2001; 98: 160-165.

39. Kronenberg HM. The role of the perichondrium in fetal bone development. Ann N Y Acad Sci 2007; 1116: 59-64.

40. Batlle E, Sancho E, Franci C, Dominguez D, Monfar M, Baulida J et al. The transcription factor snail is a repressor of $\mathrm{E}$-cadherin gene expression in epithelial tumour cells. Nat Cell Biol 2000; 2: 84-89. 